\title{
SYNTHESIS OF GEOPOLYMER FROM COAL FLY ASH AND ITS COMPARATIVE STUDY WITH FLY ASH BASED ORDINARY NEPALESE CEMENT
}

\author{
Deepa Humbahadur Gurung and Vinay Kumar Jha \\ Central Department of Chemistry, Tribhuvan University, Kirtipur, Kathmandu, Nepal.
}

\begin{abstract}
The world cement industry is responsible for 5-8 \% of the total $\mathrm{CO}_{2}$ emission. Thus, the cement industry has a crucial role in global warming. The search for an alternative green inorganic binder with improved durability led to the discovery of alkali-activated binder termed "geopolymer". In this study, geopolymer was synthesized from coal fly ash (CFA) with the parameters such as particle size $\leq 53 \mu \mathrm{m}, \mathrm{NaOH}$ concentration $8 \mathrm{M}$ and the mass ratio of $\mathrm{CFA} / \mathrm{Na}_{2} \mathrm{SiO}_{3}$ was 0.75 . For the comparative study with fly ash based cement, the cement mortars were prepared by varying the cements and mass ratio. The highest compressive strength (14.16 MPa) of the cement mortar was however obtained with 1:3 cement sand ratio after 7 days of curing, the ratio of 1:4 was considered for comparison. The cement and geopolymer mixture mortars were also prepared with varying (cement + sand) and $\left(\mathrm{CFA}+\mathrm{NaOH}+\mathrm{Na}_{2} \mathrm{SiO}_{3}\right)$ mass ratio. The maximum compressive strength of $3.84 \mathrm{MPa}$ was obtained for 1:2 mass ratio with 7 days of curing. The maximum compressive strengths of CFA based geopolymer, CFA added cement and cement and geopolymer mixture were 17.06, 21.3 and $11.42 \mathrm{MPa}$ with 90 days of curing respectively.
\end{abstract}

Keywords: Alkali activator; Cement; Coal fly ash; Compressive strength; Curing time.

\section{INTRODUCTION}

With the rapid increase in population, concrete industries are growing widely. Concrete is the most widely used construction material in the world, with the current consumption of $1 \mathrm{~m}^{3}$ per person per year'. Increase in population of Nepal has led to the increased rate of constructions. Ordinary Portland Cement (OPC) has been mostly used as a binder in building and construction works. However, cement production is attributed to:

a) $5-8 \%$ of global $\mathrm{CO}_{2}$ emissions basically due to decomposition of limestone and combustion of fossil fuels $\left(\mathrm{CaCO}_{3} \rightarrow \mathrm{CaO}+\mathrm{CO}_{2} \uparrow\right)$.

b) High energy consumption during manufacturing including heating raw materials within a rotating kiln at temperatures greater than $1400{ }^{\circ} \mathrm{C}^{2}$.

The search for an alternative green inorganic binding material with improved durability led to the discovery of alkali-activated cements. In this regard, a group of low calcium alkali-activated binder termed 'geopolymer' was pioneered by Joseph Davidovits ${ }^{3}$. The geopolymers are alkali activated alumina-silicate binders with a threedimensional amorphous structure and their properties are comparable with cement-base materials. Geopolymer technology offers low cost of the production and significant contributions to reduce $\mathrm{CO}_{2}$ emissions compared with OPC technology.

Coal Fly Ash (CFA) is one of the residues generated in the combustion of coal. It typically comprises fine, powdery particles that are predominantly spherical, solid or hollow and mostly amorphous (glassy). The chemical properties of CFA are greatly influenced by the chemical content of coal burned ${ }^{4}$. Thus we are facing two severe problems at present stage. The first one is the huge amount of CFA waste and the second one is the atmospheric pollution due to the manufacture of OPC. Hence, if it is possible to prepare geopolymers of reasonable compressive strengths with CFA waste, it can become a suitable alternative for minimizing the waste as well as for reducing the atmospheric pollution.

In the context of Nepal, fly ash production is majorly due to the coal combustion in brick and cement industries. It is estimated that there are about 200 brick factories only in Kathmandu and more than 45 cement industries all over Nepal. Thus, synthesis of geopolymer using fly ash has become a major topic of interest.

The primary work on geopolymerisation was done on kaolinite and meta-kaolinite by Davidovits ${ }^{5}$.Fixing the curing temperature at $40{ }^{\circ} \mathrm{C}$, the maximum compressive strength of $17.6 \mathrm{MPa}$ was obtained with $\mathrm{Na}_{2} \mathrm{SiO}_{3}$ to CFA mass ratio of 1.25 . Furthermore, the compressive strength was found increasing upto $20.3 \mathrm{MPa}$ with increasing curing time 6 .

The compressive strength of $48.20 \mathrm{MPa}$ was obtained for geopolymer mixture cured at $85^{\circ} \mathrm{C}$ for 28 days of curing with alkali content of 0.62 and silica content of 4.0. It was found that at higher silica content beyond the threshold value of 4.0 , leads to a reduction in reactivity showed by the decrease in compressive strength ${ }^{7}$.

Two different procedures for the use of fly ash in cement industry were compared. The first which is very often used is by adding fly ash (FA) to clinker as in the manufacture of Portland Pozzolana Cement (PPC). The second which is recent trend is to process FA and by blending it with Ordinary Portland Cement (OPC). Strength parameters were compared for both types of cements. For the same target strength of the cubes OPC blended with Processed FA (PFA) proved to be more 
economical than PPC. The most economical concrete-mix design was obtained was with $\mathrm{OPC}+25 \% \mathrm{PFA}^{8}$.

In the micro-structural comparison between geopolymers and Portland cement, X-ray diffraction revealed the presence of semi-crystalline C-S-H gel binding phase in Portland cement while geopolymer were nearly amorphous ${ }^{9}$.

\section{EXPERIMENTAL METHODS}

\section{Materials}

The starting raw material for the preparation of geopolymer i.e.CFA was obtained from Trishakti Brick Factory, Harisiddhi, Lalitpur. The $\mathrm{NaOH}$ (97\%, Qualigens Chemicals, India) and liquid $\mathrm{Na}_{2} \mathrm{SiO}_{3}(\geq 10 \% \mathrm{NaOH}, \geq$ $27 \% \mathrm{SiO}_{2}$, Sigma-Aldrich, Germany)were used as the alkali-activator solutions.

Portland Pozzolona Cement for binder and local sand for the fine aggregate were used to prepare the cement mortar specimens. The PPC was obtained from local market of Kathmandu and the sand was obtained from a local supplier available in Kirtipur. The sand was sieved and washed by using the tap water and then it was dried in sunlight.

\section{Sample Preparation}

The locally available CFA was seemed to be not completely burnt and thus it was burnt in furnace at 700 ${ }^{\circ} \mathrm{C}$ for 1 hour in order for complete conversion into its ash. The CFA was then grounded manually by using mortar and pestle to obtain fine powder. The powder was sieved by mesh of size $\leq 53 \mu \mathrm{m}$. The $\mathrm{NaOH}$ solution was prepared by dissolving the $\mathrm{NaOH}$ in distilled water to obtain $8 \mathrm{M}$ concentration.

In this study, the particle size of CFA was selected as $\leq 53$ $\mu \mathrm{m}$, the mass ratio of CFA to $\mathrm{Na}_{2} \mathrm{SiO}_{3}$ was set to $0.75: 1$ and concentration of $\mathrm{NaOH}$ was $8 \mathrm{M}$. The given conditions were chosen since, these conditions implied to higher compressive strength of geopoymer ${ }^{10}$.

\section{Synthesis of CFA Based Geopolymer}

The activator solution was prepared by mixing $12 \mathrm{~g}$ $\mathrm{Na}_{2} \mathrm{SiO}_{3}$ and $2 \mathrm{ml} \mathrm{NaOH}$ for 15 minutes. $9 \mathrm{~g} \mathrm{CFA}$ was weighed and was taken in a mortar and then the activator solution was added to it. It was then mixed until homogeneous paste was obtained. Geopolymer paste was caste into wooden moulds and was sealed to prevent water loss and then cured at $40{ }^{\circ} \mathrm{C}$ in oven for 48 hours followed by curing at room temperature $\left(25^{\circ} \mathrm{C}\right)$. The samples were then demoulded and the compressive strength was measured at $7,14,21,28$ and 90 days of curing.

\section{Preparation of Fly Ash Based Cement Mortar Cubes}

Batching of cement and sand was done by taking in the ratios of 1:3, 1:4, 1:5 and 1:6. Three samples of each ratio were prepared. The cement and sand were first dry mixed thoroughly for 1 minute and then with water until the mixture obtained uniform colour. A water/cement ratio of 0.5 was maintained. The obtained mixture was transferred to UPVC moulds by uniform shaking to ensure elimination of entrapped air. The filled moulds were kept at room temperature for 24 hours. It was then demoulded and immediately submerged into water for 7 days. After curing, the compressive strength was measured. The most appropriate ratio for cement and sand was used for further work.

With 1:4 ratio of cement to sand, the cement mortar cubes were prepared and were cured in water for 7, 14, 21, 28 and 90 days of curing. The water was renewed every 7 days and then the compressive strength was measured.

\section{Preparation of Cement and Geopolymer Mixture} Mortar Cubes

In this work five ratios of (cement + sand): (CFA + $\left.\mathrm{Na}_{2} \mathrm{SiO}_{3}+\mathrm{NaOH}\right)(2: 1,1.5: 1,1: 1,1: 1.5$ and $1: 2)$ were prepared. The cement and sand were mixed in the ratio 1:4 in the same method as that of cement mortar. The CFA and activator solution were also mixed by the same method as that of geopolymer and then they were blended together by using mortar and pestle. Three samples for each ratio was prepared and then transferred to wooden moulds and were cured at $40{ }^{\circ} \mathrm{C}$ in an oven for 48 hours. After curing the samples in oven, they were kept at room temperature and the compressive strength was measured at 7 days of preparation of the sample. The most appropriate strength was considered for further work.

With 1:2 ratio of (cement + sand): $\left(\mathrm{CFA}+\mathrm{Na}_{2} \mathrm{SiO}_{3}+\right.$ $\mathrm{NaOH}$ ), the fly ash blended cement mortar cubes were prepared and cured at $40{ }^{\circ} \mathrm{C}$ in oven for 48 hours. The samples were then kept at room temperature and the compressive strength was measured at 7, 14, 21, 28 and 90 days of curing.

\section{Measurement of Compressive Strength}

The compressive strength of the prepared geopolymer, cement mortar cubes and mixture of geopolymer and cement was measured using SLF Load from machine at Central Material Testing Laboratory, Institute of Engineering, Pulchowk Campus, Tribhuvan University. Each data of the compressive strength presented in this study is the average of three consecutive measurements.

\section{Characterization}

The raw sample and prepared geopolymer, cement mortar cubes and mixture of geopolymer and cement samples were powdered and examined by X-Ray Diffractometer (D2 Phaser Diffractometer, Bruker, Germany) using $\mathrm{CuK} \alpha$ radiation available at Nepal Academy of Science and Technology (NAST), Khumaltar, Lalitpur. Fourier Transform Infrared (FTIR) analyses of samples were performed using FTIR Spectrophotometer (IR Tracer 100, Shimadzu, Japan) in the frequency range of 4000 to 400 $\mathrm{cm}^{-1}$ at the Central Department of Chemistry, Tibhuvan University, Kirtipur.

\section{RESULTS AND DISCUSSION}

\section{Characterization of Raw and Product Materials}

\section{X-Ray Diffraction Patterns}

The X-Ray diffraction pattern of CFA, CFA based geopolymer, CFA added cement and mixture of cement and geopolymer is shown in the Figure 1. The XRD 
patterns of the samples were plotted in between $2 \theta$ angle 20 to $80^{\circ}$. Below $20^{\circ}$ there was some error in instrument due to some technical problems.

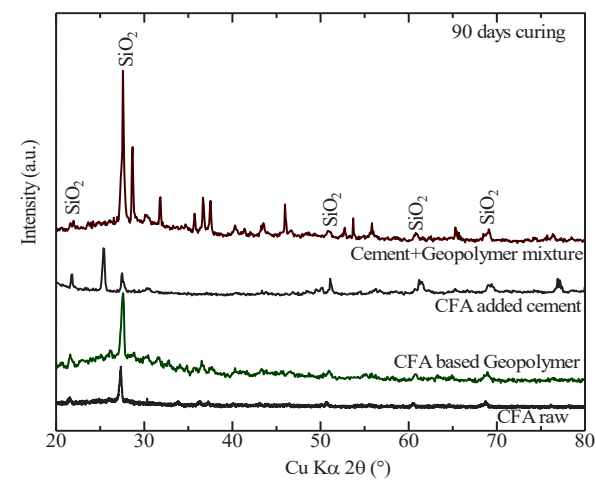

Figure 1: The XRD pattern of raw CFA, CFA based geopolymer, CFA added cement and mixture of cement and geopolymer

The peaks around $2 \theta=21,27.5,51,61$ and $69^{\circ}$ represent the presence of quartz (silica). These entire picks were prominent in cases of cement and cement+geopolymer mixture. Besides these peaks, some major peaks at $2 \theta=$ $25.4,28.7,31.8,35.7,36.6,37.5$ and $46^{\circ}$ were observed in the cases of cement and cement+geopolymer products are mainly of calcium silicate, calcium silicate hydrate, calcium aluminosilicates. The raw CFA material as well as the geopolymer product obtained from it were almost amorphous in nature except the quartz peak appearing at $2 \theta=27.5^{\circ}$. This quartz peak was also somewhat broadened in case of its geopolymer product. Furthermore, the hump appearing in the range of $2 \theta=22$ $35^{\circ}$ also confirmed the conversion of crystalline to amorphous nature of the raw materials to geopolymeric product.

The diminishing XRD peaks of the raw material after treatment with $\mathrm{NaOH}$ and sodium silicate is due to the dissolution of alumino-silicate and the formation of geopolymer products, while some of the crystalline (silica) transform into semi crystalline phases and remained as silica after the geopolymerization process ${ }^{11}$.

\section{FTIR Analysis}

The FTIR spectrum of CFA, CFA based geopolymer, CFA based cement and mixture of cement and geopolymer is shown in Figure 2.

The FTIR spectrum of CFA based geopolymer showed main absorption bands at 675, 990-1050, 1390, 2350, 3597 and $3724 \mathrm{~cm}^{-1}$. The bands in between 990 and 1050 $\mathrm{cm}^{-1}$ are major fingerprints of the geopolymeric mixture and are attributed to the $\mathrm{Si}-\mathrm{O}-\mathrm{Si}$ and $\mathrm{Al}-\mathrm{O}-\mathrm{Si}$ asymmetric stretching vibration which indicated the formation of amorphous alumino-silicate gel phase due to the dissolution of fly ash under highly alkaline conditions ${ }^{12-13}$. The peak at $1390 \mathrm{~cm}^{-1}$ is due to the stretching vibration of the $\mathrm{O}-\mathrm{C}-\mathrm{O}$ bond indicating the atmospheric carbonation ${ }^{14}$. The bands at around $450-780 \mathrm{~cm}^{-1}$ detected are due to inplane Si-O bending and Al-O linkages as well as bending $\mathrm{Si}-\mathrm{O}-\mathrm{Si}$ and O-Si-O vibration ${ }^{15}$. The band at $3597 \mathrm{~cm}^{-1}$ represents the stretching vibration of $-\mathrm{OH}$ and at 2350 $\mathrm{cm}^{-1}$ represents the stretching and bending $(\mathrm{H}-\mathrm{O}-\mathrm{H})$ vibrations ${ }^{14}$.

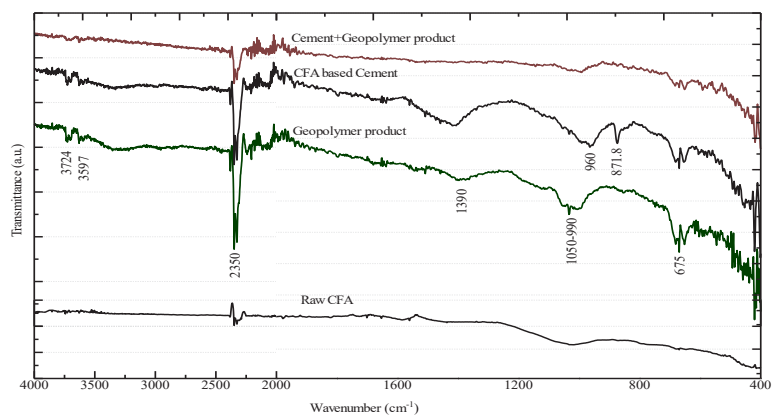

Figure 2: FTIR spectra of CFA, geopolymer product obtained from CFA, CFA based Nepalese cement and the mixture of cement and geopolymer product

The FTIR spectrum of CFA based cement sample displays a sharp band at $3640 \mathrm{~cm}^{-1}$ associated to $\mathrm{O}-\mathrm{H}$ stretching vibrations of the portlandite $\left[\mathrm{Ca}(\mathrm{OH})_{2}\right]$, a weak band at $960 \mathrm{~cm}^{-1}$ and a sharp peak at $660 \mathrm{~cm}^{-1}$ corresponding to $\mathrm{S}^{-} \mathrm{O}_{4}$ stretching mode and out-of-plane bending mode of ettringite, respectively. A shoulder near $530 \mathrm{~cm}^{-1}$ is probably due to out-of-plane $\mathrm{Si}-\mathrm{O}$ bending vibrations ${ }^{16,17}$.

Compared to geopolymer, CFA based cement showed larger absorption band near $1450 \mathrm{~cm}^{-1}$ and of the small one at $870 \mathrm{~cm}^{-1}$ corresponds to anti-symmetric stretching and out-of-plane bending modes of $\mathrm{CO}_{3}{ }^{2-}$ ions, respectively ${ }^{16,}{ }^{18}$. This observation suggests that geopolymers are less sensitive to atmospheric carbonation than cement. The principal band associated with the $\mathrm{Si}$ $\mathrm{O}(\mathrm{Al})$ stretching vibrations in $\mathrm{SiO}_{4}$ tetrahedra near 1000 $\mathrm{cm}^{-1}$ is very broad particularly for the geopolymer. It confirms that geopolymers are more disordered than Portland cement. It also appears that this $\mathrm{Si}-\mathrm{O}$ stretching band shift progressively towards greater wavenumber for geopolymer sample compared to cement sample as the $\mathrm{Si} / \mathrm{Al}$ molar ratio is decreasing.

\section{Mechanical Properties}

\section{Compresive Strength of CFA Added Cement}

The cement mortar cubes were prepared with varying cement: sand ratio. The compressive strength of cement mortar cubes with 7 days of curing for 1:3, 1:4, 1:5 and 1:6 cement: sand ratio is shown in Figure 3.

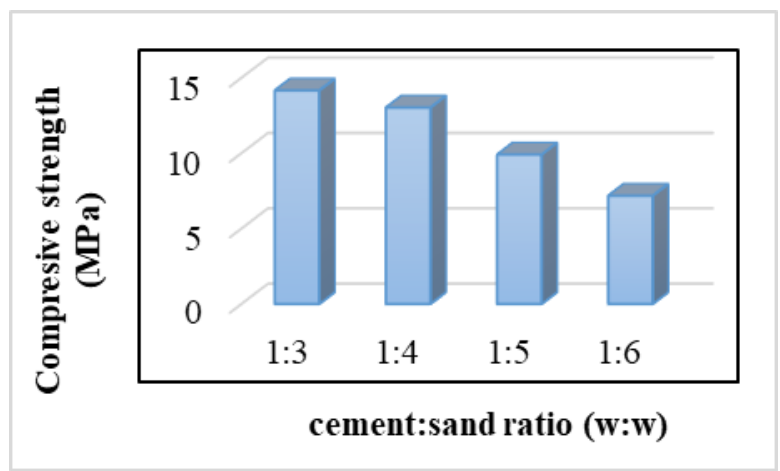

Figure 3: Compressive strength of strength of CFA added cement with varying cements and ratio.

The compressive strength decreased with decrease in amount of cement. The maximum compressive strength of 14.16 MPa was obtained when the cement: sand ratio was $1: 3$. Strength comes from inter-particle force transfer between sand grains and also from shear resistance 
provided by the cement acting as adhesive. A very high amount of sand makes the mix brittle and weak against all kinds of forces. However, cement: sand ratio of 1:4 may be considered as the economically feasible ratio and hence is chosen for further comparison with geopolymer.

\section{Compressive Strength of Cement and Geopolymer Mixture}

The cement and geopolymer mixture cubes were prepared with varying the ratio of (cement + sand): $(\mathrm{CFA}+\mathrm{NaOH}+$ $\mathrm{Na}_{2} \mathrm{SiO}_{3}$ ). The compressive strength of cement and geopolymer mixture cubes with 7 days of curing for (cement + sand): $\left(\mathrm{CFA}+\mathrm{NaOH}+\mathrm{Na}_{2} \mathrm{SiO}_{3}\right)$ ratio 2:1, 1.5:1, 1:1, 1:1.5 and 1:2 ratio is shown in Figure 4:

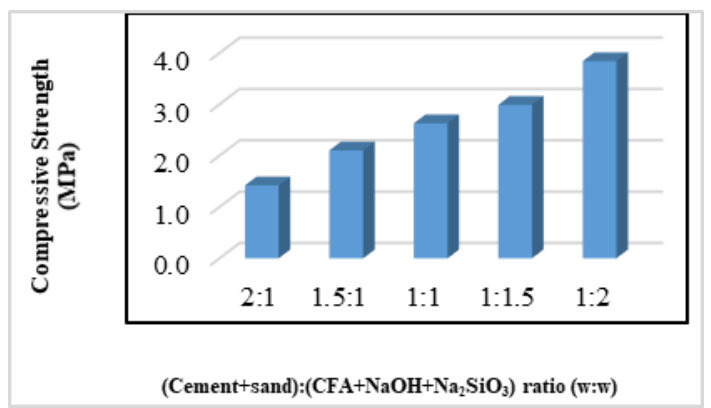

Figure 4: Compressive strength of cement and geopolymer mixture with varying ratio

The compressive strength increased with the increase in geopolymeric portion and the maximum compressive strength of $3.84 \mathrm{MPa}$ was obtained for 1:2 ratio. The conditions applied for curing favoured the geopolymer formation. The hydration products either undergo further reaction or geopolymer formation interferes with the hydration reaction.

\section{Effect of Curing Time on Compressive Strengths}

The geopolymers were prepared from CFA of particle size $\leq 53 \mu \mathrm{m}$ and $8 \mathrm{M} \mathrm{NaOH}$ while the $\mathrm{CFA} / \mathrm{Na}_{2} \mathrm{SiO}_{3}$ ratio was maintained at 0.75 . The compressive strength of the geopolymer, The CFA added cement mortar cubes with cement: sand ratio 1:4 and mixture of cement and geopolymer with (cement + sand): $(\mathrm{CFA}+\mathrm{NaOH}+$ $\mathrm{Na}_{2} \mathrm{SiO}_{3}$ ) ratio $1: 2$ obtained at $7,14,21,28$ and 90 days are represented in the Figure 5:

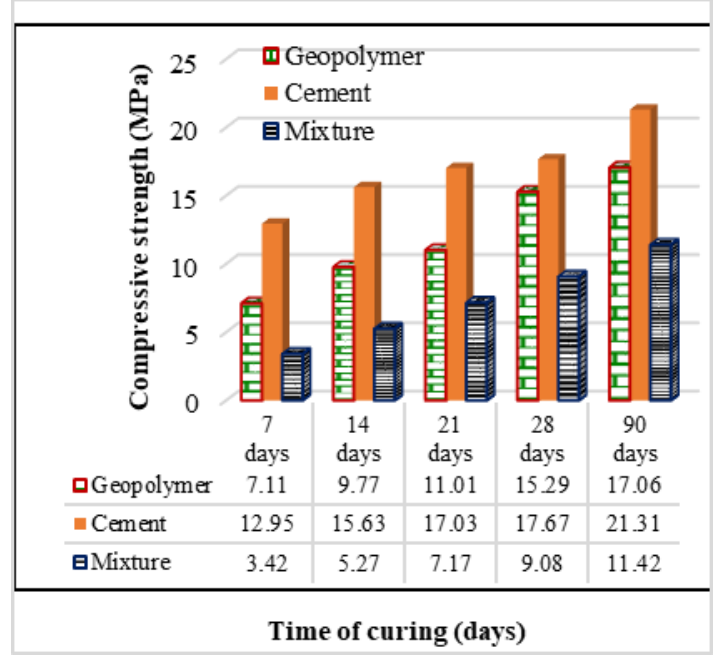

Figure 5: Compressive strength of Geopolymer, Cement and Mixture of geopolymer and cement
The compressive strength was found increasing with increase in curing time. The highest compressive strength values were found to have 17.06, 21.31 and $11.42 \mathrm{MPa}$ for 90 days curing for CFA based geopolymer, CFA added cement and cement and geopolymer mixture respectively.

In each case, the compressive strength of cement was the highest. The curing condition applied for the geopolymer synthesis was insufficient to gain higher strength than the cement cubes. The geopolymer and cement mixture cubes showed the lowest strength. In the cement samples, strength arises from the formation of $\mathrm{C}-\mathrm{S}-\mathrm{H}$ gel, the formation of which may be retarded by the presence of the geopolymer. This possibility is supported by the XRD pattern that indicates the significant presence of unhydratedtricalcium silicate $\left(\mathrm{C}_{3} \mathrm{~S}\right.$ or $\left.\mathrm{Ca}_{3} \mathrm{SiO}_{5}\right)$ in the composites, whereas in the absence of geopolymer this is completely consumed under the reaction conditions.

The $\mathrm{C}-\mathrm{S}-\mathrm{H}$ formation may be suppressed by preferential reactions of calcium or silicon with the geopolymer, making those elements less available for $\mathrm{C}-\mathrm{S}-\mathrm{H}$ formation. In the highly alkaline environment of geopolymer formation, the most likely calcium reaction would be its precipitation as hydroxide. The $\mathrm{C}-\mathrm{S}-\mathrm{H}$ has been reported to form in other highly alkaline environments, including the reaction of $\mathrm{Ca}(\mathrm{OH})_{2}$ with metakaolin activated with $\mathrm{NaOH}^{19}$ and in Portland cement activated with $18 \mathrm{M} \mathrm{KOH}$ solution ${ }^{20}$.

The preferential removal of silicon is therefore a more likely explanation. Aluminosilicategeopolymer formation can be complete at $60{ }^{\circ} \mathrm{C}$ within $5 \mathrm{~h}$ of mixing the components $^{19}$. Furthermore, geopolymer formation is reported to occur more quickly in the presence of calcium $^{21}$. The $\mathrm{C}-\mathrm{S}-\mathrm{H}$ formation is a slower reaction, and under alkaline conditions, the precipitation of calcium silicate products may not begin until after $5 \mathrm{~h}$. In highly alkaline environments, calcium species dissolve more slowly, while silica dissolves more rapidly ${ }^{22}$. Thus, the present synthesis conditions would tend to accelerate the faster geopolymerisation reaction and retard the slower $\mathrm{C}-\mathrm{S}-\mathrm{H}$ forming reaction, allowing the geopolymer to consume the available silica before calcium precipitation began. This is further supported by increased strength of the samples by retarding the rate of geopolymer formation $^{23}$.

The curing for longer time period at ambient temperature is preferable for synthesis of geopolymer. The reason behind this is as at low temperature, condensation of geopolymer precursors and evaporation of the water molecules take place simultaneously preventing the formation of voids and cracks inside the material thus increasing the compressive strength. The adequate curing improves mechanical and durable performances by accelerating and increasing the extent of chemical reaction. This suggests that curing for long time period at low temperature is preferable for the synthesis of geopolymer having high compressive strength. 


\section{CONCLUSIONS}

$>$ The FTIR and XRD analyses supported the formation of geopolymeric and cementitious materials and indicated the micro-structural changes between them.

$>$ The compressive strength of cement mortar cubes was found to change with change in cement: sand ratio giving the maximum compressive strength of 14.16 MPa at 7 days of curing for cement: sand ratio being 1:3.

$>$ For the cement and geopolymer mixture, the strength was found to increase with increase in geopolymeric material and reached up to $3.84 \mathrm{MPa}$ at 7 days of aging beingcured at $40^{\circ} \mathrm{C}$ for 48 hours for the (cement + sand): $\left(\mathrm{CFA}+\mathrm{NaOH}+\mathrm{Na}_{2} \mathrm{SiO}_{3}\right)$ ratio of $1: 2$.

$>$ The compressive strengths of CFA based geopolymer, CFA added cement and cementgeopolymer mixture increased with increase in curing time and obtained maximum compressive strength of $17.06,21.31$ and $11.42 \mathrm{MPa}$ at 90 days of curing, respectively.

\section{ACKNOWLEDGEMENTS}

We are also thankful to University Grants Commission (UGC), Bhaktapur, Nepal, for providing the Master's Thesis Research Support (UGC Grant No.: 2227). We are grateful to Mr. Siddhartha Shankar and Mr. Rajendra R. Pant for their support during compressive strength measurement of samples at the Central Material Testing Laboratory, Pulchowk, Lalitpur. We are also grateful to Dr. Suresh Kumar Dhungel of Nepal Academy of Science and Technology (NAST) for the support to get X-ray diffraction measurements of the samples.

\section{REFERENCES}

1. Gartner, E. 2004. Industrially interesting approaches to "low- $\mathrm{CO}_{2}$ " cements. Cement and Concrete Research. 34-9: 1489-1498.

2. Davidovits, J. 2015.Geopolymer chemistry and application ( $4^{\text {th }} E d n$.), Institute Geopolymer Publishers, France.

3. Davidovits, J. 1994. Properties of geopolymer cements.Proceedings of the 1 st International Conference on Alkaline Cements and Concretes, Ukraine: 131-149.

4. Meyers, J.F., Raman, P. and Bernadette S.K. 1976. Federal Highway Administration, Report No.FHWA-IP-76-16, Washington DC.

5. Davidovits, J. 1984. Synthetic mineral polymer compound of the silicoaluminates family and preparation process.US Patent $4,472,199$.

6. Jha, V.K. and Budhamagar, G.P. 2012. Synthesis of geopolymer from coal fly ash.Journal of Nepal Chemical Society, 30: 24-28.

7. Thakur, R.N. and Ghosh, S. 2009. Effect of mix composition on compressive strength and microstructure of fly ash based geopolymer composites. ARPN Journal of Engineering and Applied Sciences. 44: 68-74.

8. Rajdev, R., Yadav, S. and Sakale, R. 2013. Comparison between portlandpozzolana cement and processed fly ash blended ordinary portland cement. Civil and Environmental Research. 3- 6: 24-29.

9. Lecomte, I., Henrist, C., Liegeois, M., Maseri, F., Rulmont, A. and Cloots, R. 2006. (Micro)-structural comparison between geopolymers, alkali-activated slag cement and Portland cement.Journal of the European Ceramic Society. 26: 3789-3797.

10. Devkota, D. 2016. Mechanochemical Characteristics of Geopolymer Synthesized from Coal Fly Ash Waste. M.Sc. Dissertation, Central Department of Chemistry, Tribhuvan University, Kathmandu, Nepal.

11. Lukman, A., Hamzah, F. and Maharani A. 2011.Crystalline phase reactivity in the synthesis of fly ash-based geopolymer.Indonesian Journal of Chemistry. 11- 1: 90-95.

12. van Jaarsveld, J.G.S., van Deventer, J.S.G. and Schwartzman, A 1999. The potential use of geopolymeric materials to immobilise toxic metals: Part II. Material and leaching characteristics. Minerals Engineering. 12- 1: 75-91.

13. Fernandez-Jimenez, A. and Palomo, A. 2005. Composition and microstructure of alkali activated fly ash binder: Effect of the activator.Cement and Concrete Research. 35- 10: 1984-1992.

14. Zarina, Y., Al Bakri, A.M.M., Kamarudin, H., Khairul, N.I., Rafiza, A.R. and Andrei, V.S. 2015. Effect of solids-to-liquids, $\mathrm{Na}_{2} \mathrm{SiO}_{3}$-to- $\mathrm{NaOH}$ and curing temperature on the palm oil boiler ash $(\mathrm{Si}+\mathrm{Ca})$ geopolymerisation system.Materials. 8- 5: 2227-2242.

15. van Jaarsveld, J.G.S., van Deventer, J.S.J. and Lukey, G.C. 2002.The effect of composition and temperature on the properties of fly ash- and kaolinite-based geopolymers.Chemical Engineering Journal. 89: 63-73.

16. Mollah, M.Y.A., Lu, F. and Cocke, D.L. 1998. An X-ray Diffraction (XRD) and Fourier Transform Infrared Spectroscopyic (FT-IR) characterization of the speciation of arsenic (V) in Portland cement type-V. Science of The Total Environment. 224: 57-68.

17. Hanna, R.A., Barrie, P.J., Cheeseman, C.R., Hills, C.D., Buchler, P.M. and Perry, R. 1995. Solid state ${ }^{29} \mathrm{Si}$ and ${ }^{27} \mathrm{Al}$ NMR and FTIR study of cement pastes containing industrial wastes and organics. Cement and Concrete Research. 25- 7: 1435-1444.

18. Yu, P., Kirkpatrick, R.J., Poe, B., McMillan, P.F. and Cong, X. 1999. Structure of calcium silicate hydrate (C-S-H): near-, mid-, and far-infrared spectroscopy. Journal of the American Ceramic Society. 82- 3: 742-748.

19. Alonso, S. and Palomo, A. 2001. Alkaline activation of metakaolin and calcium hydroxide mixtures: influence of temperature, activator concentration and solids ratio. Materials Letters. 471\&2: $55-62$

20. Richardson, I. G. 2004. Tobermorite/jennite- and tobermorite/calcium hydroxide-based models for the structure of $\mathrm{CSH}$ : applicability to hardened pastes of tricalcium silicate, $\beta$ dicalcium silicate, Portland cement, and blends of Portland cement with blast-furnace slag, metakaolin, or silica fume. Cement and Concrete Research. 34: 1733-1777.

21. Nicholson, C.M., Murray, B.J., Fletcher, R.A., Brew, D.R.M., MacKenzie, K.J.D. and Schmucker, M. 2005. Proceedings of World Geopolymer Conference, Paris. pp. 31-33.

22. Barnes, P. and Bensted, J. 2002. Structure and Performance of Cements $\left(2^{\text {nd }} E d n.\right)$, Spon Press, London.

23. Tailby, J. and MacKenzie, K.J.D. 2010. Structure and mechanical properties of aluminosilicategeopolymer composites with Portland cement and its constituent minerals. Cement and Concrete Research. 40: 787-794. 